\title{
Leaders
}

\section{Exercise in cardiac rehabilitation}

There is a saying that "what goes around comes around", and exercise training as a treatment for patients suffering from coronary heart disease is no exception to the rule. The eighteenth century English physician, William Heberden, recorded the case of a patient suffering from angina "who set himself the task of sawing wood every day and was nearly cured". ${ }^{1}$ Almost a century later in 1854, the Irish doctor, William Stokes wrote "the symptoms of debility of the heart are often removable by a regulated course of gymnastics, or by pedestrian exercise". ${ }^{2}$ His "pedestrian cure" consisted of comfortable walking initially on level ground, the distance and gradient being increased as tolerance improved-always, however, cautioning against excessive fatigue, breathlessness, or chest pain. Have we progressed that far since then? Over the ensuing years, Stokes' exercise training regime was largely forgotten, obscured by the teaching of the London surgeon John Hilton, who stressed the value of strict bed rest. ${ }^{3}$ Unfortunately Hilton's precept was carried to extremes. Prolonged immobilisation in bed became the cornerstone of medical care for close to a century; seldom was it practiced more assiduously than after a myocardial infarction. However, by the 1950s, doctors had begun to question the wisdom of strict bed rest, and when Levine and Lown introduced their innovative and highly successful "armchair treatment", in which they progressed their heart attack patients to sitting up in a chair by the bed a few days after admission, the era of early mobilisation had arrived. ${ }^{4}$

From mobilisation to exercise training is a short step, and when Chapman and Fraser, from the University of Minnesota, catheterised patients recovering from myocardial infarction during treadmill exercise and showed that their cardiovascular responses were normal, they paved the way for the introduction of exercise training regimens. ${ }^{5}$ During the 1960s, a handful of doctors began to involve their cardiac patients in aerobic conditioning programmes. A major problem during those early years, however, was the perception of the patient who had suffered myocardial infarction as a chronic invalid. It was partly to offset this situation and also to show the high level of fitness that could be achieved in selected subjects by supervised training that we entered seven coronary patients from the Toronto programme in the 1973 Boston marathon. ${ }^{6}$ Their completion of the run without mishap was a medical first. It focused considerable attention on cardiac exercise rehabilitation, and did much to convince patients and public alike that most heart attack survivors who had completed a progressive exercise training regimen could lead not only a full and active life, but could accomplish something that was beyond their physical capacity even before their attack. Today, exercise training remains a cornerstone of cardiac rehabilitation and the secondary prevention of coronary disease. In combination with other strategies, such as smoking cessation and a prudent low fat diet, it has been shown to reduce symptoms, increase cardiopulmonary fitness, improve lipid profile, ameliorate high blood pressure, counter obesity and adult onset diabetes, enhance fibrinolysis, improve endothelial dysfunction, alleviate depression, improve quality of life, and reduce the incidence of sudden death and recurrent fatal myocardial infarction. ${ }^{78}$ Certainly, a formidable list! Initially offered to patients recovering from myocardial infarction and coronary artery bypass graft surgery, cardiac rehabilitation exercise programmes are now extended to stable chronic heart failure patients, as well as heart transplantation recipients, angioplasty patients, pacemaker and left ventricular assist device recipients, and those recovering from valve surgery. More recently, exercise training has emerged as having a role to play in strategies to stabilise or reverse the atherosclerotic process. In America, the Ornish Lifestyle Program combined regular daily exercise with a low fat diet and stress reduction techniques to obtain plaque reversal in a small group of coronary patients. ${ }^{9}$ Although no attempt was made to determine the impact of the various interventions, and one would suspect that the rigorous low fat diet would emerge as the prime candidate, exercise training would nevertheless appear to be a valuable component. On the other hand, a similar regression trial carried out by Schuler in Heidelberg, Germany, which also obtained stabilisation and reversal in a significant number of treated patients, compared the effectiveness of its American Heart Association Step 2 low fat diet with a vigorous exercise training protocol. ${ }^{10}$ Of the two interventions, the exercise training regimen was found to be more closely associated with plaque reversal than diet.

Thus the past five decades of the twentieth century have seen noteworthy advances in the application of exercise training as part of a comprehensive approach for the secondary prevention and rehabilitation of coronary heart disease. As a result, national and international health bodies have stressed the importance of exercise rehabilitation, and have advocated that it be made available to all cardiac patients. Unfortunately, in most countries this goal has not been achieved. Cardiac rehabilitation is grossly undervalued and underused, and it has been estimated that only about $20-30 \%$ of potential candidates receive the service. Greater efforts are required on the part of government, health professionals, and the public alike if we are to meet the challenge of providing improved cardiac rehabilitative care for patients into the next century.

TERENCE KAVANAGH

Professor, Graduate Program in Exercise Sciences, and Medical Director, Toronto Rehab Cardiac Rehabilitation and Secondary Prevention Program, University of Toronto

1 Heberden W. Commentaries on the history and cure of diseases. London: T Payne, 1802.

2 Stokes W. The diseases of the heart and the aorta. Dublin: Hodges \& Smith, 1854

3 Hilton J. Rest and pain. London: G Bell \& Sons Ltd, 1863.

4 Levine SA, Lown B. "Armchair" treatment of acute coronary thrombosis. FAMA 1952;148:1365-9.

5 Chapman C, Fraser R. Studies on the effect of exercise on cardiovascular function: cardiovascular responses to exercise inpatients with healed myocardial infarction. Circulation 1954;9:347-51.

Kavanagh T, Shephard RJ, Pandit V. Marathon running after myocardial infarction. $\mathscr{f} A M A$ 1974;229:1602-5.

7 National Institutes of Health. Physical activity and cardiovascular health. A national consensus. Leon AS, ed. Champaign, IL: Human Kinetics, 1997.

8 Kavanagh T. Take heart. Toronto: Key Porter Books, Ltd, 1998.

9 Ornish D, Brown SE, Scherwitz LW, et al. Can lifestyle changes reverse coronary heart disease? The lifestyle heart trial. Lancet 1990;336:129-33.

10 Hambrecht R, Niebauer J, Marburger C, et al. Various intensities of leisure time physical activity in patients with coronary artery disease: effects of cardiorespiratory fitness and progression of coronary atherosclerotic lesions. F Am Coll Cardiol 1993;22:468-77. 


\section{The stigmatisation and denial of mental illness in athletes}

A patient asks for your help with fatigue, which she has been experiencing for the past several weeks. She says she is having increasing difficulty carrying out her daily responsibilities, lacks motivation and energy, and is irritable and discouraged. She reports trouble sleeping, is often late to her scheduled responsibilities, is not performing as well as previously in her job and other roles, and has had several minor injuries and mild headache and back pain.

If you are a family doctor or general practitioner, you would suspect that this woman has a major depressive disorder (MDD), although the likelihood that a depressed patient would actually present her symptoms in such a clear and obvious fashion is extraordinarily low. However, if you are a sports doctor and the patient is a competitive athlete, you may label her as being burned out, overtrained or stale, depending on your personal nomenclature for this problem. You may carry out a routine battery of laboratory tests, often including measuring a variety of immunological, hormonal, and haematological variables, consult with the athlete's coach about a modified training schedule, and suggest the athlete consider a trial of rest which may even include cessation of all training and competition. On the other hand, the primary care doctor would recommend some combination of counselling and/or medication for the non-athlete patient, with an active treatment programme designed to maintain the patient's roles and responsibilities.

Why the dramatic difference in approach to labelling, diagnosing, and treating what appears to be the same disease? Three issues stand out when attempting to answer this question.

(1) Despite the known beneficial and protective effect of exercise on mental illness, ${ }^{1}$ athletes are still susceptible to depression and other mental illness, although perhaps at a lower prevalence than the general population. ${ }^{2}$

(2) Athletes may be even more susceptible to underdiagnosis and inadequate treatment of depression and other mental illness than are non-athletes, ${ }^{3}$ particularly for problems that are related to athletic training and performance and are viewed from a narrow physiological rather than a broader biopsychosocial perspective.

(3) The current conceptualisation of and approach to mental illness in athletes is fraught with stigmatisation, denial, and dichotomous paradigms of "psychological" versus "physical" disease, which are inaccurate, unhelpful, and deprive the athlete of effective care.

The similarities between "depression", as a psychiatric disease, and "overtraining", as a consequence of overly intense athletic training, are remarkable both for their number and strength, as well as for their denial by many sports doctors and psychologists. Current nomenclature defines overreaching as a short term decrement in performance in which recovery may take a few days to weeks, usually through a temporary and modest decrease in training load. ${ }^{4}$ Overreaching is the athletic equivalent of an adjustment reaction, grieving, or a more minor depression in which psychosocial loss or stressors lead to a temporary decrement in social or work function. Overtraining (OT) is defined as a long term decrement in performance, ${ }^{4}$ usually with various physiological, immunological, hormonal, and metabolic changes that are remarkably similar to those in MDD, the only difference being the nature of the role dysfunction: athletic performance in the case of the overtrained athlete, social, cognitive, and work in the case of the depressed patients.

The similarities between OT and MDD extend to immunological effects, in which natural killer cell and humoral immunological parameters are suppressed in both, leading to an increased risk of upper respiratory infection. In fact, the $\mathrm{J}$ shaped curve relating exercise to immunological function ${ }^{5}$ is equally appropriate to describe the relation between exercise and mood, in which both too little and too much exercise correlate with increased levels of irritability and depression, and moderate exercise is associated with the lowest level of mood disturbance.

Both OT and MDD are related to central fatigue, with similar alterations in neurotransmitter levels and function. ${ }^{6}$ Elevated and unsuppressed cortisol secretion are found in both OT and MDD. ${ }^{7}$ Both depressed patients and overtrained athletes have decreased sensitivity to noradrenaline (norepinephrine) and dopamine, decreased levels of growth hormone, lutrophin, $\beta$-endorphins, and thyrotrophin, and increased levels of corticotrophin-releasing hormone leading to hypercortisolism. Similar changes may also occur in both MDD and OT in brain monoamines, including tryptophan and serotonin. ${ }^{6}$ These intriguing similarities are enhanced by the highly anecdotal, but common and often successful, use of serotonergic antidepressants in overtrained athletes. These athletes report both early and delayed benefits in their energy, motivation, and training similar to those reported by depressed patients in mood, energy, and role function.

Perhaps the most telling comparison of OT and MDD is in the denial and avoidance of each diagnosis by the respective patient groups. There is a common response that the disease represents a personal failure, a loss of willpower, and a defect in character, and is a problem of which one is ashamed and hides. ${ }^{8}$ Patients reject the implications of loss of control, diminished vitality, and inadequate coping skills that both diagnoses carry, and often vow to work harder so as to overcome their inadequacies, which usually leads to even more severe symptoms and dysfunction. Athletes with OT are particularly susceptible to harm from these myths because of their heightened levels of goal orientation and task mastery.

In summary, competitive athletes are special in many ways, including a high level of goal orientation, a commitment to intense physical training and competition, and a decreased risk of depression and possibly other mental illnesses. But the risk of depression is not eliminated, and may be reflected, at its most severe level, in what sports doctors and scientists currently call OT. MDD as a neuropsychiatric disorder causes profound chemical and role dysfunction that is remarkably similar to the effects of OT in athletes, the major difference being that the role dysfunction in athletes relates to the major role in their life - athletic training and performance. Most importantly, the stigmatisation of and denial by athletes with OT, similar to the behaviour of patients with MDD, are preventing sports doctors and scientists from a proper study and treatment of overtrained athletes. OT deserves a broader, more enlightened, biopsychosocial approach if we are to help athletes with this devastating problem.

THOMAS L SCHWENK Department of Family Medicine, University of Michigan Health System 
1 Paluska S, Schwenk TL. Physical activity and mental health: current concepts. Sports Med 1999; in press.

政 an WP, Goldston SE, eds. Exercise and mental health. New York: Hemisphere Publishing, 1987:145-53.

3 Hirschfield RMA, Keller MB, Panico S, et al. The National Depressive and Manic-Depressive Association consensus statement on the undertreatment of depression. $\mathcal{F} A M A 1997 ; 277: 333-40$.

4 Kreider RB, Fry AC, O'Toole ML. Overtraining in sport: terms, definitions, and prevalence. In: Kreider RB, Fry AC, O’Toole ML, eds. Overtraining in sport. Champaign, IL: Human Kinetics, 1998:viii.
5 Nieman DC. Exercise, upper respiratory tract infection, and the immune system. Med Sci Sport Exerc 1994;26:128-39.

6 Keizer HA. Neuroendocrine aspects of overtraining. In: Kreider RB, Fry AC, O'Toole ML, eds. Overtraining in sport. Champaign, IL: Human Kinetics, 1998:145-67.

7 Keizer HA, Kuipers H, deHaan J, et al. Effect of a 3-month endurance training program on metabolic and multiple hormonal responses to exercise. Int F Sports Med 1987;3:154-60.

8 Simon GE, VonKorff M, Piccinelli M, et al. An international study of the relation betwen somatic symptoms and depression. $N$ Engl f Med 1999;341:1329-35.

\section{Exercise and the prevention of back pain disability}

Back pain is an important health and social problem. Over the last 30 years the amount of time lost from work because of spinal problems has increased across all developed countries. In the United Kingdom, there was a $266 \%$ increase in the days of Invalidity Benefit paid for spinal disorders in the 10 years to $1994 .{ }^{1}$ Since then, Incapacity Benefit has replaced Invalidity Benefit, and the number of days of benefit paid for spinal disorders (for periods of greater than six months) has stabilised at around 90 million a year (DSS figures). Notwithstanding this increase in benefit payments, the prevalence of back pain in the general population appears unchanged. ${ }^{1}$ This suggests that there may be an epidemic of back pain disability rather than an epidemic of back pain itself. About one in six of the population report having back pain on any one day, one in three sometime in the last month, and $6 \%$ will have had long standing or serious disabling low back pain in the previous year. ${ }^{12}$ In 1993, the annual cost to the NHS of treating back pain was estimated at $£ 481$ million, and the nonNHS costs of treating back pain was estimated at $£ 197$ million. ${ }^{3}$ Even a small percentage reduction in disability could have a large impact on both NHS costs and the nonNHS costs borne by individuals and their private insurers.

Many different, general and specific, exercise programmes are advocated for the treatment and prevention of back pain disability. Convincing evidence of a clinically important effect has not been found for any regimens recommending specific spinal exercises for acute back pain. ${ }^{4}$ There is research evidence that the resumption of normal activities shortens the duration of acute and subacute episodes of back pain, leading to the assumption that chronic disability will also be reduced. ${ }^{5}$ The evidence review for the United Kingdom national guidelines for the management of acute low back pain considers the diagnosis and treatment of acute back pain in detail. ${ }^{5}$ The guidelines recommend that patients with back pain who do not have nerve root compression or reasons to suspect a serious underlying condition should be classified as having "simple back pain". It is thought that encouraging those who develop simple back pain to resume normal activity, including exercise, as soon as possible will reduce the proportion who develop long term disability and is very unlikely to cause significant harm.

Data on the effect of recreational exercise on the development of back pain disability in symptom free people are sparse. Because few symptom free people progress to back pain disability and because there are significant problems ensuring compliance with an exercise regimen, any community based randomised controlled trial to show an effect of exercise would be unfeasibly large. A number of controlled trials in the workplace have suggested that exercise can reduce the incidence of back disability. ${ }^{6}$ A 1994 review of observational studies concluded that increased general fitness, or spinal flexibility, may have a slight protective effect against the future development of back pain. ${ }^{7}$ Most of the studies included were workplace, not community, based. Two long term studies, one Finnish workplace study ${ }^{8}$ and one Danish population study, ${ }^{9}$ published too late to be included in the review, also suggested that physical activity protects against the development of back pain. A recent population study based in two general practices in South Manchester followed a cohort of back pain free people for one year. Sporting activity had no effect on the incidence of back pain in men but increased its incidence in women. ${ }^{10}$ These observational data must be interpreted with caution because the majority were obtained in the workplace, not the general population, and there is the possibility that unknown confounding factors could have affected the results. Most published studies do, however, suggest that regular general exercise has some protective effective.

In summary, the evidence on the effect of recreational exercise on the development of back pain in the general population is not conclusive. As regular physical activity is thought to reduce the proportion of those with back pain that progress to established disability, it is plausible to hypothesise that regular recreational exercise before the onset of pain would have a similar effect. Controlled trial evidence obtained in workplace settings supports this. Although the evidence for exercise preventing back problems is weak, the other potential benefits of exercise mean that it is reasonable to encourage regular physical activity as part of a strategy to reduce the overall impact of back pain disability, on both the individual and society overall.

I am funded by an NHS R\&D Primary Care Career Scientist Award. The views expressed in this article are my own and do not necessarily represent the views of my employers.

Department of General Practice and Primary Care

MARTIN R UNDERWOOD

Queen Mary and Westfield College

Mile End, London E1 4NS

email:m.underwood@mds.qmw.ac.uk

1 Anon. Epidemiological review: the epidemiology and cost of back pain. The annex to the clinical standards advisory group's report on back pain. London: HMSO, 1994

2 Croft P, Papageorgiou A, McNally R. Low back pain. In: Stevens A, Raftery J, eds. Health care needs assessment: the epidemiologically based needs assessment

3 Moffett JK, Richardson G, Sheldon TA, et al. Back pain. Its management and cost to society. NHS centre for reviews and dissemination. Discussion paper cost to society. NHS centre for reviews and dissem

4 van Tulder M, Koes BW, Bouter LM. Conservative treatment of acute and chronic nonspecific low back pain. Spine 1997;22:2128-56.

5 Waddell G, Feder G, McIntosh A, et al. Low back pain: evidence review. London: Royal College of General Practitioners, 1999. Also available at http://www.rcgp.org.uk/college/activity/qualclin/guides/backpain/ index.htm

6 van Poppel MN, Koes BW, Smid T, et al. A systematic review of controlled clinical trials on the prevention of back pain in industry. Occup Environ Med 1997;54:841-7.

7 Lahad A, Malter AD, Berg AO, et al. The effectiveness of four interventions for the prevention of back pain. $\mathcal{F} A M A 1994 ; 272: 1286-91$

8 Leino PI. Does leisure time physical activity prevent low back disorders? Spine 1993;18:863-71.

9 Harreby M, Hesseøe G, Kjer J, et al. Low back pain and physical exercise in leisure time in 38-year-old women: a 25 -year cohort study. Eur Spine $\mathcal{F}$ 1997;6:181-6.

10 Croft PR, Papageorgiou AC, Thomas E, et al. Short-term physical risk factors for new episodes of low back pain. Prospective evidence from the South Manchester back pain study. Spine 1999;24:1556-61. 


\section{The social patterning of exercise behaviours: the role of personal and local resources}

The "inverse care law"-that is, those most in need of services are least well provided with them-is well known as it applies to health care. ${ }^{1}$ It may, however, be less often considered in relation to local provision for health promoting activities. Much health promotion advice focuses on individuals, and exhorts them to engage in better personal habits, or to encourage their children to do so. It is often noted that such messages are differentially taken up by different social class groups; better off and better educated people are more likely to modify their diets, give up smoking, improve dental hygiene practices, and take up healthy physical activities than are poorer and less well educated people. ${ }^{2}$ The lower take up of healthy behaviours among lower social class groups is often considered to contribute to their poorer health and mortality experiences, although such health behaviours do not in fact completely explain social class gradients in morbidity or mortality. ${ }^{3}$ It is often assumed that the barriers to the take up of health promotion messages lie in personal factors such as lack of motivation, fatalism or short termism, or lack of personal resources such as money, time, equipment, or knowledge. However, "the inverse care law" may apply to opportunities to take up health promoting messages as much is it does to the provision of health care.

Since 1987, we have been studying socially contrasting localities in Glasgow City, Scotland. As well as looking at residents in different age groups (teenagers and adults in early and later middle life), we have been directly measuring socially structured features of the local social and physical environment that might enhance or inhibit people's opportunities to be healthy or live healthy lives. ${ }^{4}$ As part of this study, we have examined, among other things, primary care provision, social work provision, public transport, the price and availability of healthy foods, retail shopping services, crime rates, perceptions of "incivilities" in the local environment, community groups, and facilities for physical recreation. ${ }^{45}$ In the case of all these features of the local environment, we have found a pattern that we call "deprivation amplification"- that is, in places where people are poorer, iller, and have fewer personal resources such as money or private transport, local facilities that may enable people to lead healthy lives are also poorer. In the case of physical activity, for instance, in our more socially deprived area, we found the following: there were fewer formal resources for healthy physical recreation-for example, bowling greens, tennis courts, sports centres; fewer residents had access to cars, and public transport was sparser and less frequent, and thus it was harder for people to travel elsewhere to use such facilities; there were fewer safe open green spaces where people could walk, jog, or take their children to play; children's playgrounds were less attractive and safe; and there were more perceived threats in the immediate environment (for example, graffiti, litter, discarded injection equipment, risk of assaults and muggings, disturbances from youths) which were likely to deter people from walking or cycling around in the local area, or letting their children play outside. ${ }^{6}$ Perhaps not surprisingly, residents in this area were less likely to engage in physical activity than were those in better provided for areas. ${ }^{78}$

Recent United Kingdom policies on public health give high priority to reducing inequalities in health, and in common with earlier such policies, ${ }^{910}$ also prioritise improvement in health related behaviours such as increasing physical activity. The English white paper, Saving lives: our healthier nation, states that the government will build on many existing initiatives including "wide-ranging and affordable sports and leisure opportunities at local neighbourhood level" ${ }^{11}$ However, the currently inequitable distribution of such opportunities is not discussed (although the inequitable distribution of food outlets is discussed on the next page). The Scottish white paper, Towards a healthier Scotland, states that the government will set up a task force to develop a national physical activity strategy for Scotland, and set targets for increasing physical activity among young people and adults. ${ }^{12}$ However, although an overarching priority is to tackle inequalities, no targets are given for improved life circumstances that may enhance people's ability to engage in more physical activity. Indeed a key feature of the Scottish white paper is that, although targets are set for lifestyles and health topics, no targets are set for improvements in life circumstances despite these being seen as key determinants of lifestyles and of morbidity and mortality. ${ }^{12}$ Although there are difficulties in setting targets for the reduction in inequalities in health because of the potentially long time lag between life circumstances and health consequences, there seems no reason why there should not be targets for the reduction of inequitable life circumstances that are known to influence health outcomes. Thus the government could have taken the opportunity to set targets for every community of certain size (in terms of either area or population) to have access to certain basic provisions for physical activity - for example, safe play areas for children, green open spaces, and safe well lit streets and pavements. In keeping with the emphasis on the importance for health of "active living" for most of the sedentary population-for example, accumulating 30 minutes of moderate activity such as walking on most days of the week, ${ }^{13}$ - a key issue in reducing inequalities in health and in levels of physical activity is a reduction of physical and social barriers to everyday opportunities for physical activities in people's local environments.

SALLY MACINTYRE

Director, MRC Social and Public Health Sciences Unit

University of Glasgow, 4 Lilybank Gardens, Glasgow G12 8RZ

email:Sally@msoc.mrc.gla.ac.uk

1 Tudor Hart J. The inverse care law. Lancet 1971;i:405-12.

2 Acheson D. Independent inquiry into inequalities in health: report. London: TSO, 1998.

Marmot MG, Davey Smith G, Stansfield S, et al. Health inequalities among British civil servants: the Whitehall II study. Lancet 1991Jun:1387-93.

4 Macintyre S, Maciver S, Sooman A. Area, class and health; should we be focusing on places or people? Fournal of Social Policy 1993;22:213-34.

5 Sooman A, Macintyre S. Health and perceptions of the local environment in socially contrasting neighbourhoods in Glasgow. Health and Place 1995;1:15-26.

6 Macintyre S, Ellaway A. Local opportunity structures, social capital and social inequalities in health: what can central and local government do? Australian Fournal of Health Promotion (in press).

Ellaway A, Macintyre S. Does where you live predict health related behaviours? A case study in Glasgow. Health Bull (Edinb) 1996;54:443-6. 8 Macintyre S, Ellaway A. Social and local variations in the use of urban neighbourhoods: a case study in Glasgow. Health and Place 1998;4:91-4.

9 Department of Health. The health of the nation: a strategy for health in England. London: HMSO, 1992.

10 Scottish Office. Scotland's health: a challenge to us all. Edinburgh: HMSO, 1992.

11 Department of Health. Saving lives: our healthier nation. London: The Stationery Office, 1999

12 Scottish Office Department of Health. Towards a healthier Scotland: a white paper on health. Edinburgh: The Stationery Office, 1999.

13 Pate R, Pratt M, Blair S, et al. Physical activity and public health. $¥ A M A$ 1995;273:402-7. 